\title{
The impact of renovation plasters on desalting and drying of damp walls
}

\author{
Wactaw Brachaczek ${ }^{*}, 1$ \\ ${ }^{1}$ University of Bielsko-Biala, Faculty of Materials, Civil and Environmental Engineering \\ ul. Willowa 2, 43-300 Bielsko-Biala, Poland
}

\begin{abstract}
Renovation plasters have been used in the construction industry since the early 1970s. Although the benefits they offer are obvious, there were also critical opinions about the adverse effect of the plasters on the durability of the walls. The complaints mainly concerned the tendency of renovation plasters to accumulate water in the wall, which in the winter time resulted in peeling of the plasters. As a result, more and more often conservators began to refrain from applying renovation plasters in historic buildings in favour of lime plasters without the porosity-increasing additions. The article presents an analysis of the walls which can be encountered in the renovation practice. For selected buildings undergoing renovation, the moisture content of walls, their strength, microstructure and water sorption were determined. Renovation plasters, whose microstructure and properties matched the properties of the walls, were used for their renovation. Plasters with optimal microstructure enabled salt accumulation, crystallized salts did not lower their durability and did not lead to cracking or peeling.
\end{abstract}

\section{Introduction}

All structures become degraded over time. External factors, which can be divided into atmospheric and biological processes, the interaction of water with salts dissolved in it and mechanical factors, are an important impact here [1-3]. The porous structure of the materials used to make the walls, the lack of damp-proof insulation as well as the incorrect drainage of rainwater results in damping of the walls. One of the mechanisms of moisture penetration into the walls is the capillary transport of water from the ground. The walls, along with moisture, are penetrated by ions of mineral salts. As a result of their impact, the peeling of paint coatings, destruction of plasters and the development of fungi and moulds occurs. The way to stop these unfavourable processes is to cut off the supply of water transporting soluble salts [3]. However, if no further measures are taken to reduce the humidity of the walls, they will still become destroyed. The wall may, but may well not, dry up. This phenomenon is affected by the degree of salinity, microstructure, sorptivity, etc. One of the ways of reducing dampness in walls is using renovation plasters $[4,5]$. They are used in the comprehensive renovation of damp and salted walls, in which, in addition to the reconstruction of damp-proof insulation, agents for preventing biological corrosion are

* Corresponding author: wbrachaczek@ath.bielsko.pl 
used. Depending on the characteristics, two basic categories of these plasters are distinguished: salt transporting and accumulating and hydrophobic ones [6]. Good efficiency in salt removal and accumulation is achieved by combining transporting and accumulating plasters with hydrophobic plasters into one system. Although renovation plasters have been used for several decades, and in many cases the benefits of using them are obvious, there were also critical opinions. In many cases, it turned out that by using them the water was retained in the walls, and their drying up was impaired. Initially, it was thought that the causes of the problems were related to workmanship errors and they were not taken too seriously. After conducting detailed analyses, it turned out that they were caused by their properties $[2,4,7,8]$.

This paper presents the results of changes in humidity of walls renovated using renovation plasters whose microstructure and properties were matched to the properties of the walls. Plasters with optimal microstructure enabled salt accumulation, crystallized salts did not lower their durability and did not lead to cracking or peeling.

\subsection{The process of wall drying}

A wall with a layer of plaster can be considered as a two-layer system. During drying, moisture transport will take place in the liquid phase and in the gas phase. In the first stage of drying, the moisture movement is determined by filling of the capillaries with water, the formation of menisci. The flow rate of moisture in the liquid phase from the wall to the plaster layer is influenced by the relationship between the pore structures of these materials.

In double-layered systems consisting of a porous substrate covered with a layer of plaster, the moisture transport, with different pore sizes, is determined by the difference in capillary pressure $[9,10]$. Liquid pressure $p_{L}[\mathrm{~Pa}]$ can be determined as the difference in pressure between the surroundings $p_{A}$ and the liquid in a single capillary $p_{C}$, using the Laplace equation (4.2):

$$
\mathrm{p}_{\mathrm{L}}=\mathrm{p}_{\mathrm{A}}-\mathrm{p}_{\mathrm{C}}=-\frac{2 \cdot \gamma \cdot \cos \theta}{\mathrm{r}_{\mathrm{m}}}+\mathrm{p}_{\mathrm{A}}
$$

where: $\mathrm{p}_{\mathrm{L}}$-liquid pressure in a given section $(\mathrm{Pa}), \mathrm{r}_{\mathrm{m}}$ - radius of pores filled with water $(\mathrm{m})$, $\Theta$ - contact angle $\left({ }^{\mathrm{O}}\right), \gamma$ - surface tension $(\mathrm{Nm}), \mathrm{p}_{\mathrm{A}}-$ ambient pressure $(\mathrm{Pa})$.

It can be concluded that in a specific small segment of the material, mobile liquid fills all the capillaries with radii smaller than $r_{m}$. As a result of the pressure gradient presence, pores with a smaller diameter tend to suck water from pores with a larger diameter [9-11]. With the progress of drying, the humidity of the wall will gradually decrease, and the air will enter the larger pores where lower surface tension is present. At material humidity below the critical humidity $\mathrm{X}_{\mathrm{kr}}$ the moisture is retained in the plaster. The plaster pores will be covered with a static layer of moisture. The water adsorbed on the surface of the pores does not flow, creating a static film. Along with a further decrease in the moisture content of the plaster, the thickness of the sorption film on the surface of the pores decreases, and thus the diameter of the pores filled with moisture $r_{m}$ decreases (the $r_{m}$ radius corresponding to the thickness of the sorption film). Further drying is related to the lack of continuity of the sorption film and the emergence of clusters. Evaporation of the clusters occurs due to the difference in the vapour pressure around the clusters and the vapour pressure of the dry layer [12]. 


\subsection{The impact of plaster microstructure on wall drying}

Research carried out by the author of the publication demonstrated that both the total porosity of plasters and the pore size distribution had an impact on the speed of wall drying [12]. Fig. 1a shows the total time of drying of walls made of SB silicate bricks, HFB Cadien bricks, GB gothic bricks and SS sandstone from full saturation to $0.03 \mathrm{~kg} / \mathrm{kg}$ of moisture content. The walls were covered with single layers of plasters: hydrophobic HF with a total porosity of $41.6 \%$, porous with a total porosity of $32.7 \%$ (Plaster 1 ), porous with a porosity of $52.1 \%$ (Plaster III) and two layers of plasters: porous with a porosity of $52.1 \%$ and a hydrophobic one. In Polish literature, walls with a moisture content below 3\% of mass humidity are treated as dry walls [14]. Figure $1 \mathrm{~b}$ shows the changes in the speed of drying of walls depending on their humidity.
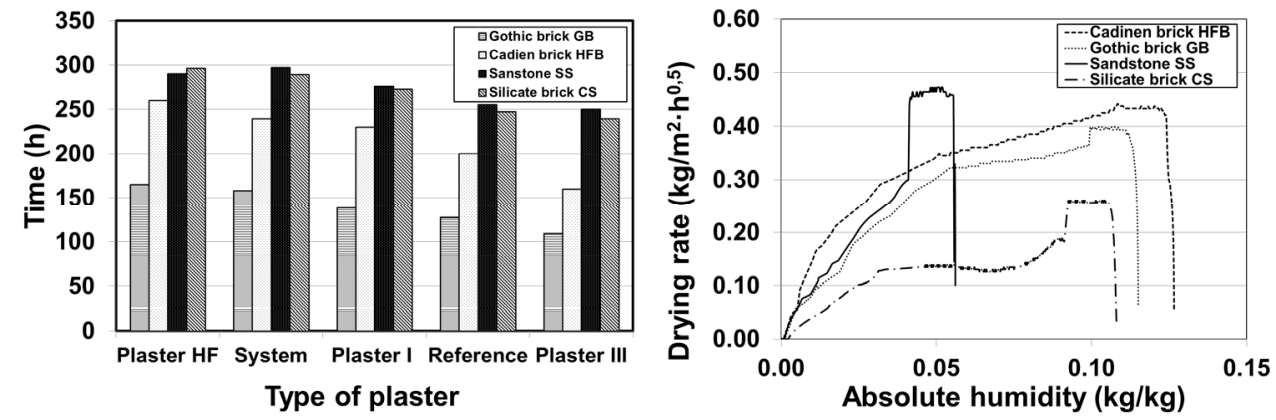

Figure 1. The total time of wall drying from full saturation to $0.03 \mathrm{~kg} / \mathrm{kg}$ moisture content (a), the dependence of the drying rate $\left(\mathrm{kg} /\left(\mathrm{m}^{2} \cdot \mathrm{h}^{0,5}\right)\right)$ on the moisture content in wall $(\mathrm{kg} / \mathrm{kg})(\mathrm{b})$, determined for walls made of: GB Gothic, HFB Cadien brick, SS sandstone and SC silicate brick, covered with one layer of HF hydrophobic plaster with a porosity of $41.6 \%$, porous plasters with a total porosity of 32.7 (Plaster I) and $52.1 \%$ (Plaster III), and System of two layers of plasters: porous plaster (Plaster III) and hydrophobic plaster HF.

Low porosity plasters with a narrow low-diameter pore size range can contribute to delaying drying of building substrates and even to accumulating water in plasters. Plasters, in addition to capillary active pores with a diameter of 0.1 to $60 \mu \mathrm{m}$, should have pores with diameters above $100 \mu \mathrm{m}$ to allow moisture transport through the diffusion of water vapour. Adopting the total porosity of a renovation plaster as the basic criterion determining the suitability of the plaster for renovation of damp and salty walls may be insufficient, and in some cases may lead to faster destruction of the walls. An important aspect in the selection of plasters for renovation of damp walls is the pore size analysis of the substrate. Plasters should be selected in such a way as to assure a pressure gradient caused by the capillary action of the plaster against the substrate and not to impair the water vapour diffusion.

\section{Experimental}

\subsection{Purpose of the research}

The impact of the microstructure of renovation plasters on the drying of damp walls was analysed on the example of five buildings entered into the List Of Historic Buildings.

The scope of work included determining the humidity of walls, their degree of salinity, strength, microstructure, and sorption. To the wall properties determined in this way, renovation plasters with optimal microstructure and sorption were matched. Investigation of wall humidity changes after renovation. 


\subsection{Determination of macroscopic and microscopic properties of the walls}

As part of the renovation works of buildings with saline and damp walls, their moisture and saltiness level was measured, as well as strength properties, density of total porosity and sorption of bricks taken from the wall were examined. Moisture measurement was carried out using the GE Porosimeter Surveymaster meter and the drying and weighing method. Humidity measurements were made from the outside of the walls. For each measurement point, 4 readings were made at a height of $10 \mathrm{~cm}, 60 \mathrm{~cm}, 110 \mathrm{~cm}$ and $160 \mathrm{~cm}$ above the ground level. The average humidity and average salt load of the walls of the examined buildings, from the front side, at a height of $10 \mathrm{~cm}$ from the ground level is summarized in Table 1 . The physical properties of bricks sampled from the buildings are summarized in Table 3 .

Table 2 shows the degree of salt load according to the WTA Merkblatt 2-9-04/D:200510 [6], according to which the walls were classified in the appropriate category.

Table 1. Average humidity of the front walls of buildings undergoing renovation.

\begin{tabular}{|c|c|c|c|c|c|c|c|}
\hline $\begin{array}{c}\text { Buil- } \\
\text { ding } \\
\text { No. }\end{array}$ & Building & $\begin{array}{c}\text { Year of } \\
\text { construc } \\
\text { tion }\end{array}$ & Wall material & \multicolumn{2}{|c|}{$\begin{array}{c}\text { The content of salt ions in } \\
\text { walls (\%) w/w }\end{array}$} & \multirow{2}{*}{$\begin{array}{c}\text { Humid } \\
\text { ity [\%] }\end{array}$} \\
\cline { 4 - 7 } 1 & $\begin{array}{c}\text { Church of St. Barbara } \\
\text { in Swornegacie }\end{array}$ & 1916 & $\begin{array}{c}\text { Full brick - cement and } \\
\text { limestone plaster }\end{array}$ & 0.09 & 0.46 & 0.02 & $\mathbf{1 8 . 5}$ \\
\hline 2 & $\begin{array}{c}\text { Building at Orkana St. } \\
\text { in Bielsko-Biała }\end{array}$ & $\begin{array}{c}1890- \\
1930\end{array}$ & $\begin{array}{c}\text { Full brick - cement and } \\
\text { limestone plaster }\end{array}$ & 0.19 & $\mathbf{1 . 6 2}$ & 0.49 & $\mathbf{1 2 . 6}$ \\
\hline 3 & $\begin{array}{c}\text { Nativity of the } \\
\text { Blessed Virgin Mary } \\
\text { Church in Bieniszew }\end{array}$ & $\begin{array}{c}1760- \\
1781\end{array}$ & $\begin{array}{c}\text { A brick and stone wall } \\
\text { plastered with limestone } \\
\text { plaster - hollow wall }\end{array}$ & 0.08 & 1.2 & 0.0 & $\mathbf{1 2 . 5}$ \\
\hline 4 & $\begin{array}{c}\text { Louis Dame's villa } \\
\text { in Katowice }\end{array}$ & 1924 & $\begin{array}{c}\text { Full brick - cement and } \\
\text { limestone plaster }\end{array}$ & 0.08 & 0.49 & 0.02 & $\mathbf{1 1 . 2}$ \\
\hline 5 & $\begin{array}{c}\text { The building at 10 } \\
\text { Cechowa St. in } \\
\text { Bielsko Biała }\end{array}$ & 1862 & $\begin{array}{c}\text { Full brick - cement and } \\
\text { limestone plaster }\end{array}$ & 0.07 & 0.46 & 0.08 & $\mathbf{1 1 . 2}$ \\
\hline
\end{tabular}

Table 2. Classification of salt load [6].

\begin{tabular}{|l|c|c|c|}
\hline Salting level & Chlorides in \% w/w & Sulphates in \% w/w & Nitrates in \% w/w \\
\hline High & $>\mathbf{0 . 5}$ & $>\mathbf{1 . 5}$ & $>\mathbf{0 . 3}$ \\
\hline Medium & $0.2-0.5$ & $0.5-1.5$ & $0.1-0.3$ \\
\hline Low & $<0.2$ & $<0.5$ & $<0.1$ \\
\hline
\end{tabular}

Table 3. Average properties of bricks sampled from buildings undergoing renovation.

\begin{tabular}{|c|c|c|c|c|c|c|c|c|}
\hline Material & $\begin{array}{c}\text { Density } \rho \\
\left(\mathbf{k g} / \mathrm{m}^{3}\right)\end{array}$ & $\begin{array}{c}\mathrm{S}(\boldsymbol{\rho})^{*} \\
\left(\mathrm{~kg} / \mathrm{m}^{3}\right)\end{array}$ & $\begin{array}{c}\text { Porosity } \\
\text { Pc (\%) }\end{array}$ & $\begin{array}{l}\mathbf{S}(\mathbf{P})^{*} \\
(\%)\end{array}$ & $\begin{array}{c}\text { Water sorption } \\
\text { ratio A } \\
\left(\mathbf{k g} /\left(\mathbf{m}^{2} \cdot \mathbf{t}^{0.5}\right)\right)\end{array}$ & $\begin{array}{c}\mathrm{S}(\mathrm{A})^{*} \\
\left(\mathrm{~kg} /\left(\mathrm{m}^{2} \cdot \mathrm{t}^{0.5}\right)\right)\end{array}$ & $\begin{array}{l}\text { Strength } \\
\text { Rc (MPa) }\end{array}$ & $\begin{array}{l}\text { S(R)* } \\
\text { (MPa) }\end{array}$ \\
\hline Building I & 1,564 & 87 & 21 & 4.2 & 16.4 & 1.2 & 11 & 2.2 \\
\hline Building II & 1,412 & 156 & 31 & 6.5 & 22.5 & 1.3 & 5.8 & 3.9 \\
\hline Building III & 1,342 & 128 & 28 & 5.2 & 24.2 & 0.98 & 3.4 & 2.3 \\
\hline Building IV & 1,526 & 66 & 22 & 3.1 & 15.2 & 1.23 & 4.2 & 1.9 \\
\hline Building V & 1,553 & 68 & 19 & 2.9 & 14.3 & 1.35 & 9.4 & 0.8 \\
\hline
\end{tabular}

(*) The table presents the average mean values of these parameters together with the average square error of the mean value $\mathrm{S}(\mathrm{x})$. Source: own research.

Mass humidity measurement results for the walls of the building dated at the turn of the 18th and 19th century located at the intersection of Orkana and Nad Niprem streets in Bielsko-Biała are shown in Table 4, the salt load results are included in Table 5. Measurements were made for the front (southern) wall from the street side and from the north side (courtyards). 
Table 4. Measurement of the mass humidity of the wall: front external (southern) and yard-side external (northern) wall.

\begin{tabular}{|c|c|c|c|c|c|c|c|c|c|c|c|c|c|c|c|}
\hline \multirow{2}{*}{$\begin{array}{l}\text { Height of the } \\
\text { measuring point }\end{array}$} & \multicolumn{7}{|c|}{ Mass moisture (\%) North wall } & \multicolumn{8}{|c|}{ Mass moisture (\%) South wall } \\
\hline & 1 & 2 & 3 & 4 & 5 & 6 & 7 & 1 & 2 & 3 & 4 & 5 & 6 & 7 & 8 \\
\hline $160 \mathrm{~cm}$ & 3,8 & 2,6 & 3,2 & 2,5 & 2,7 & 2,9 & 3,6 & 3,2 & 2,2 & 3,7 & 1,9 & 2,4 & 2,8 & 2,1 & 3,6 \\
\hline $110 \mathrm{~cm}$ & 6,9 & 4.4 & 6,1 & 4,2 & 5,4 & 5,0 & 6,5 & 6,2 & 4,2 & 6,6 & 4,8 & 4,7 & 7,2 & 3,5 & 6,8 \\
\hline $60 \mathrm{~cm}$ & 9.6 & 83 & 8.9 & 6,7 & 8.2 & 8,1 & 8,6 & 8,8 & 8,4 & 9.2 & 10,5 & 9.2 & 11,3 & 7,8 & 10,6 \\
\hline $10 \mathrm{~cm}$ & 13,1 & 11,8 & 12,5 & 11,3 & 11,9 & 12,2 & 14,2 & 11,7 & 13,8 & 13,2 & 14,1 & 14,2 & 15,2 & 15,0 & 15,6 \\
\hline
\end{tabular}

$(*)$ Height of the measuring point in relation to the ground level, source: own research

Analysing the results presented in Table 4, it was found that the highest level of mass humidity occurred at a height of $10 \mathrm{~cm}$ above ground level. As the height on the wall increased, the mass humidity gradually decreased. At a level of $160 \mathrm{~cm}$, for each measuring point, the mass humidity was low or very low. The distribution of the humidity level and its decrease together with the increase of the measurement height clearly indicated the capillary rise of moisture from the ground side.

Table 5 presents the average weight amounts of salt for the front (south) wall from the street side and for the north side (yard).

Table 5. Averaged salinity of the outer front wall from the street side (south) and from the yard side (north).

\begin{tabular}{|l|c|c|c|c|}
\hline \multicolumn{4}{|c|}{ Degree of salinity (\%) w/w } \\
\hline & \multicolumn{2}{|c|}{ South wall } & \multicolumn{2}{c|}{ North wall } \\
\hline Nitrates $\left(\mathrm{NO}_{3}{ }^{-}\right)$ & 0.19 & medium & 0.06 & low \\
\hline Sulphates $\left(\mathrm{SO}_{4}{ }^{2-}\right)$ & $\mathbf{1 . 6 2}$ & medium & 0.37 & low \\
\hline Chlorides $\left(\mathrm{Cl}^{-}\right)$ & 0.49 & low & 0.00 & low \\
\hline
\end{tabular}

For the analysed buildings, (Table 1) the level of salinity due to the chloride content was determined to be at medium and low levels. The highest chloride content was found for a wall adjacent to the street (Figure 2a). The source of the chlorides were defrosting agents used in the winter season. In the walls on the side of the yard and adjacent tenement houses, the chloride content was close to zero. The reasons for the increased concentration of nitrates and sulphates is the migration of salt with capillary rise water and the age of the building. Observing the conditions of the façade of the buildings it can be assumed that the sulphate salts mostly came from exhaust fumes. This is evidenced by the increased sulphate content in the walls, as well as the resulting damage occurring on the whole façade surface (figure $2 b$ ).
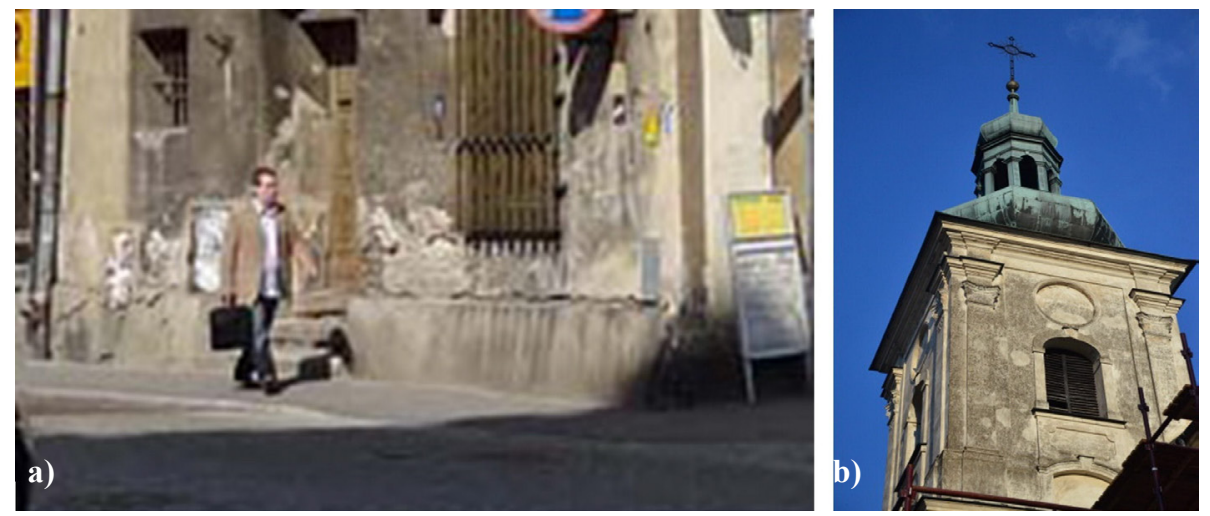

Figure 2. The plinth of the building at Orkana St. in Bielsko-Biała (a), Tower of the Nativity of the Blessed Virgin Mary Church in Bieniszew (b). 
In the case of the first, fourth and fifth building (Table 1), the amount of salts in the walls is at a low level and does not affect the durability of the plaster (WTA 2-9-04 instruction [6]. For the second building, the concentration of sulphate salts exceeded $1.5 \%$, which corresponded to a high salt load. It is a quantity that may impair the durability of a typical plaster coating. In the crystallization process, sulphate salts increase their volume, which results in numerous cracks and plaster splitting. The concentration of sulphate salts in the building 3 will have a similar effect on the durability of the plasters (Table 1).

Figure 3 presents the pore size distribution of bricks sampled from the buildings on which the renovation was carried out. Such distribution allows to specify which range of dimensions is the most common for these pores; furthermore it explains whether the pore distribution is mono- or polymodal.

To determine the pore size distribution Carlo-Erba 4000 mercury porosimeter was used. The pore size distribution of the equivalent diameter from $7.5 \mu \mathrm{m}$ to $1.8 \mathrm{~nm}$ was obtained by determining the volume of mercury which, when gradually increasing the pressure, fills the pores of increasingly lower diameter. The pore diameter of up to $200 \mu \mathrm{m}$ was determined by measuring the mercury penetration when equalizing the pressure to atmospheric pressure (after degassing and filling with mercury).

a)

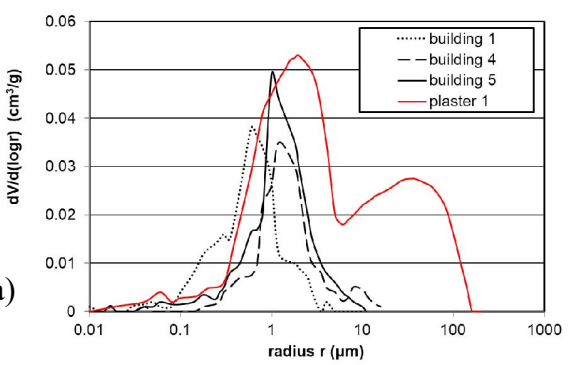

b)

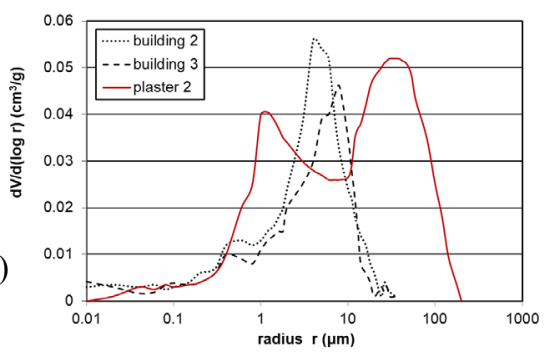

Figure 3. Pore size distribution depending on the radii: for the walls of buildings 1, 4, 5 (Fig. 3a), for the walls of buildings 2, 3 (Fig. 3b). The pore size distribution for the walls is plotted in black, while the pore size distribution proposed for the renovation primer plasters is plotted in red.

Analysing the pore size distribution of materials from individual buildings (Figure 3) it was found that in the case of buildings 1,4 , and 5 it is monomodal. The pore diameters do not exceed $10 \mu \mathrm{m}$. In walls of buildings 2 and 3, the pore distribution, also monomodal with a larger diameter range. Based on the design documentation, it can be concluded that the age of the buildings impacts microstructure differences.

\subsection{Selection of wall drying technology and its implementation}

Carrying out renovation works of historic buildings with damp and salted walls requires an individual approach both in terms of the selection of materials and the technology. Currently there is no standard for testing the effectiveness of damp-proof barriers, nor guidelines and technical conditions for the implementation and acceptance of renovation works [15].

This paper presents an innovative solution consisting in the application of two kinds of hydrophilic porous plasters, differing in the pore size distributions, and a hydrophobic renovation plaster. The differentiation of the water sorption coefficients, as well as the pore size distribution of the plasters: 1 and 2 was intended by the author. Plasters with diversified microstructure were obtained by optimizing the composition of the recipe. The pore size distribution of hydrophilic (primer) plasters is presented in Figure 4.

The obtained porous plasters are characterized by variations in the pore size (Figure 4). The pore size distribution of the porous plaster 1 is polymodal. The largest pore volume corresponds to pores with a diameter from 0.3 to $6 \mu \mathrm{m}$, and then from 6 to $160 \mu \mathrm{m}$. For the 


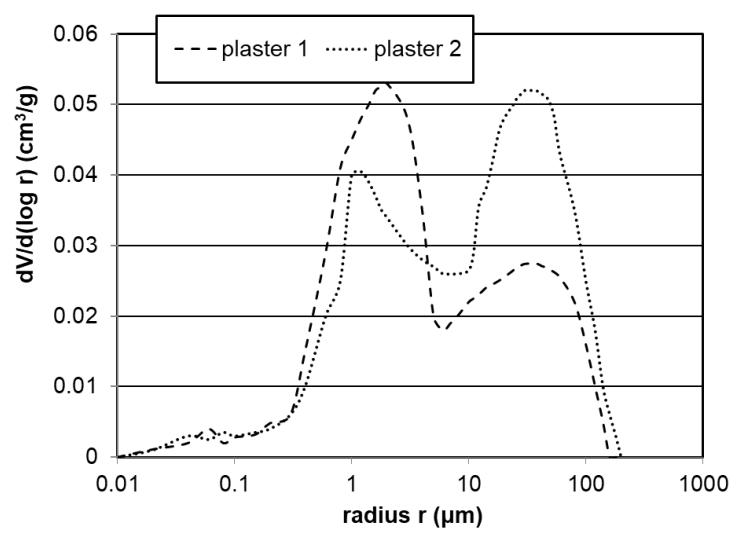

Figure 4. Pore size distribution of the porous primer plasters (plaster 1 and plaster 2) with a porosity of 48 and $54 \%$ (source: own research).

most part they are capillary active pores. In the case of porous plaster 2 , the highest pore volume corresponds to diameters from 0.4 to 6 and then from 10 to $200 \mu \mathrm{m}$. Plasters differ in the sorption coefficient; with plaster 1 characterized by A coefficient of $24\left(\mathrm{~kg} /\left(\mathrm{m}^{2} \cdot \mathrm{h}^{0.5}\right)\right)$ and plaster 2 characterized by A coefficient of $18.2\left(\mathrm{~kg} /\left(\mathrm{m}^{2} \cdot \mathrm{h}^{0.5}\right)\right)$. Differences in the sorption coefficient A result from the porosity of the plasters. For plaster 2, the number of air pores is greater than in plaster 1 (Figure 4). The air pores interrupt the moisture flux caused by the capillary pressure difference.

The innovative approach of the author to the renovation of damp and salted walls consists in the use of a renovation plaster system including:

- rough coat applied as openwork in a semi-opaque manner, $5 \mathrm{~mm}$,

- renovation primer plaster with a narrow or wide pore size distribution, $10 \mathrm{~mm}$,

- renovation hydrophobic plaster, $15 \mathrm{~mm}$,

- decorative and protective coating in the form of silicone paint applied twice on previously primed substrate.

Priming plaster 1, in which the capillary active pores prevail, is intended for humid substrates of low salt load. Building materials consisting of walls with a low sorption coefficient are slower to absorb water, and if they become damp, harder to release it [13]. As shown in the porosimetric studies, building materials from the walls of buildings 1,4 and 5 were characterized by a narrow range of diameters of pores, whose size did not exceed $10 \mu \mathrm{m}$. The sorption coefficient A was lower than in the case of bricks from buildings 2 and 3. For these walls, Plaster 1 may prove to be a good solution. The pore size range of the porous Plaster 1 allows obtaining a differentiation in the pore diameters between the substrate and the plaster, and thus accelerates the drying of the walls. Figure 3 presents the pore size distribution of bricks characterized by a narrow range of pore sizes with the plotted pore size distribution of the porous plaster 1 . It can be noted that the pore size of wall materials coincides with the pore sizes of plaster 1. According to equation (1), as a result of the capillary pressure gradient, pores with a smaller diameter tend to suck water from pores with a larger diameter.

The primer plaster 2 , in addition to the capillary active pores, contains air pores that interrupt the flow of moisture adsorbed by the plaster from the substrate. At the same time, these pores constitute a sort of ventilation system for renovation plasters, allowing the walls to dry out by water vapour diffusion. Due to the fact that moisture evaporates on the surface of these pores, the salt concentration in the moisture is so high that most salts crystallize. For this reason, the plasters are intended to be used for the renovation of walls with medium and high salt load. Figure 5 presents the microstructure of porous renovation plasters with varied pore sizes. Both the pores with a diameter of several and several hundred 
micrometres can be seen here. The absorption of moisture solutions from the walls is influenced by pores with a diameter of up to $70 \mu \mathrm{m}$. Figure 3 presents the distribution of pore sizes of materials from the walls of buildings 2 and 3 (black) compared to the distribution of the pore sizes for plaster 2. Also in this case, the pore sizes of both the plaster and the bricks are the same.
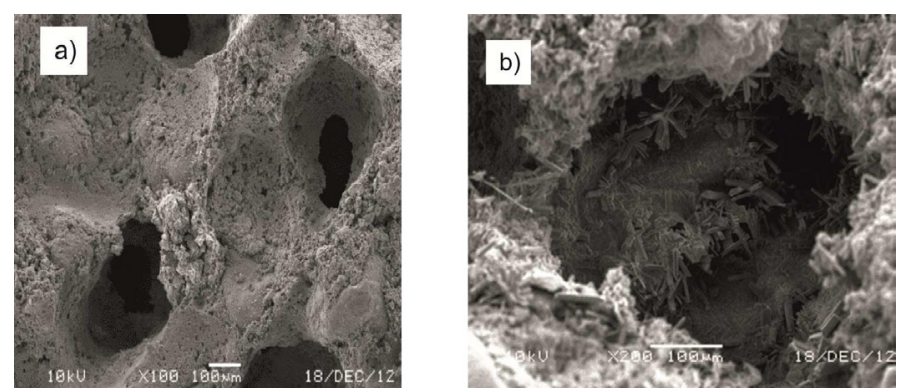

Figure 5. A microscope image showing the structure of the pores in the renovation plaster: a) freshly after hardening; b) containing crystallized salts (source: own research).

In the hydrophobic plaster, due to the low sorptivity, the flow of moisture in the liquid phase is limited. This is the very concept of this plaster, whereby, primarily, the salts are not transported outside the façade, which causes efflorescence, and secondly, water does not penetrate the wall from the outside. Moisture transport through this plaster takes place through the diffusion of water vapour. Therefore, the plaster should have pores with diameters ranging from a few dozen to several hundred micrometres, so as not to limit the diffusion of water vapour.

\subsection{Results of wall moisture measurement after renovation}

Changes in average humidity for the walls of buildings listed in Table 1 after subsequent years after renovation are shown in Figure 6.

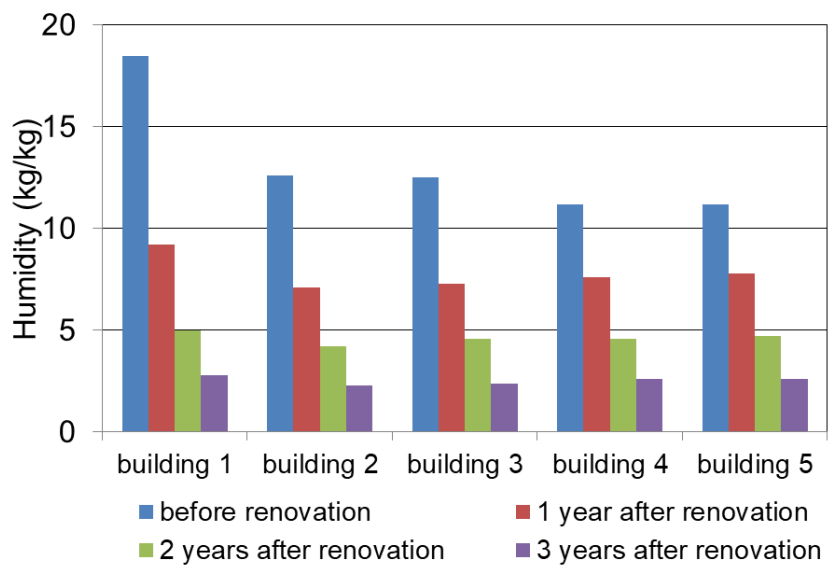

Figure 6. Changes in average humidity for the walls of buildings listed in Table 1 after subsequent years after renovation.

Observations made on buildings demonstrated that the walls before renovation were in poor condition and their mass humidity was above $12 \%$. The mass humidity determined 2 years after renovation, at a height of $30 \mathrm{~cm}$ above the ground level, decreased by more 
than half. Walls with such humidity can be classified as low humidity category. The average humidity determined at a height of $100 \mathrm{~cm}$ is lower and amounts to $2.96 \%$. It is a low humidity, which does not affect the durability [1]. As demonstrated by the results, in order to avoid water retention in the wall, renovation plasters used for renovation should have their properties adapted to the properties of the substrate. The microstructure and sorption properties of plasters will impact wall drying.

\section{Conclusions}

Bricks in historic walls differ in their physical properties such as strength, porosity, resistance to water and atmospheric factors (e.g. acid rain). Porosity of the walls depends on the type of material and the time and intensity of environmental factors. The pore size distribution and the sorptivity of the walls are also different. Depending on these properties, the walls dry with a varying intensity. In some cases, renovation plasters may slow down the process of wall drying or contribute to moisture retention.

When applying renovation plasters, the speed of wall drying was influenced both by their total porosity and the pore size distribution. An important aspect in the selection of plasters for renovation of damp walls is the microscopic properties analysis of the substrate. The solution proposed by the author consisting in applying plasters of varying microstructure for the renovation of damp walls seems to be the proper direction allowing to influence the speed of wall drying. Plasters should be selected in such a way as to assure a pressure gradient caused by the capillary action of the plaster against the substrate and not to impair the water vapour diffusion.

\section{References}

1. M. Collepardi, Cem. Concr. Compos., 21.2, 147-154 (1999)

2. M. Pavlíková, et al. Constr. Build. Mater., 25.3, 1205-1212 (2011)

3. Brachaczek, W., Inż. Bud., 2, 75-82 (2015)

4. B.Lubelli, , R. PJ Van Hees, C. WP. Groot, Constr. Build. Mater., 20.9: 691-699. 2006

5. W. Brachaczek, (Analiza wieloczynnikowa parametrów fizycznych w modelowaniu technologicznym tynków renowacyjnych, 2014)

6. WTA Merkblatt 2-9-04, „Sanierputzsysteme”.

7. D. Michoniová, Zprávy památkové péče, 65, 313-316 (2005)

8. E.Vejmelková, et al., Constr. Build. Mater.,31, 22-28 (2012)

9. C.Hall, W. D. Hoff, (Water transport in brick, stone and concrete. CRC Press, 2004)

10. C. Hall, W. D. Hoff, P. R. S. Mathematical Physical and Engineering Sciences 463(2084) 1871-1884 (2007)

11. A. Alsabry, Przegląd budowlany, 81.9, 46-48 (201)

12. J.Wyrwał, (Ruch wilgoci w porowatych materiatach i przegrodach budowlanych. Dział Wydawnictw WSI, 1989)

13. W. Brachaczek, Periodica Polytechnica Civil Engineering, 62.3, 792-799 (2018)

14. J. Adamowski, Z. Matkowski, (Osuszanie i renowacja budynków zalanych wodą. Izolacje przeciwwilgociowe. XXX Jubileuszowe Ogólnopolskie „Warsztaty Pracy Projektanta Konstrukcji WPPK, 2: 1-44, 2015)

15. M.Rokiel, C. Magott, (Renowacje obiektów budowlanych: projektowanie $i$ warunki techniczne wykonania i odbioru robót. Dom Wydawniczy Medium, 2013) 